\title{
Readily Available Highly Active [Ti]-Adamantyl-BINOL Catalysts for the Enantioselective Alkylation of Aldehydes
}

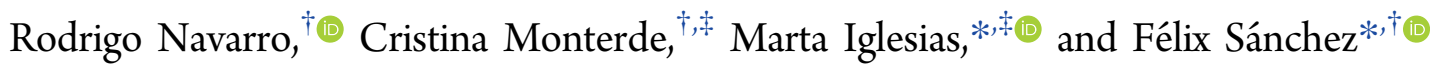 \\ ${ }^{\dagger}$ Instituto de Química Orgánica (CSIC), Madrid 28006, Spain \\ ${ }^{\ddagger}$ Materials Science Factory, Instituto de Ciencia de Materiales de Madrid (CSIC), Madrid 28049, Spain
}

Supporting Information

ABSTRACT: A series of enantiopure (R)-adamantyl 1,1'binaphthalene-2,2'-diols were successfully synthesized in a straightforward one-step reaction from commercial products with excellent overall yields. The activity of chiral titanium catalyst derived from (R)-3,6,6'-tri(adamantan-1-yl)-[1,1'binaphthalene]-2,2'-diol ligand, $(\boldsymbol{R})-(2)-\mathbf{T i}$, in the enantioselective asymmetric alkylation of aldehydes is significantly enhanced (up to $98 \%$ yield and $99 \%$ ee).

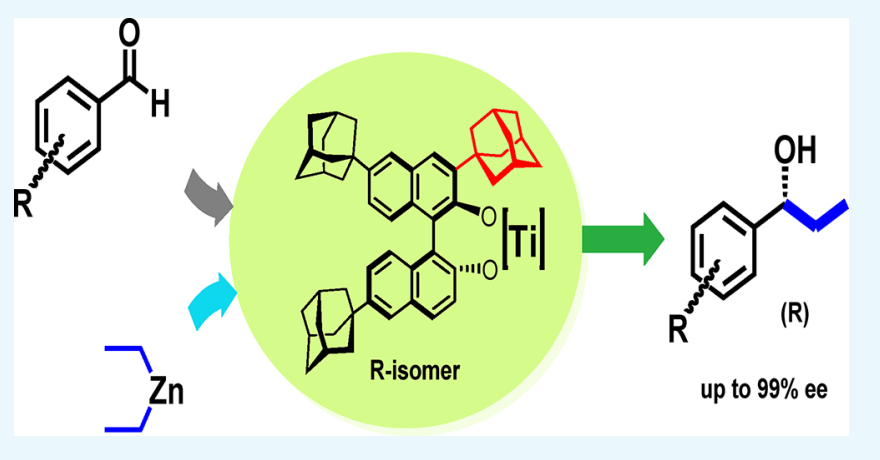

These useful reagents may serve both as starting materials in the synthesis of single-stereoisomer drugs or intermediates. Recently, it has been reported that a sterically demanding aryl group at the 3 position of BINOLs significantly improved the catalytic performance of the chiral titanium catalyst derived from the resulting ligands. ${ }^{3,4}$ Herein, we describe the implementation of an approach for the fast simple synthesis of hindered BINOLs bearing bulky alkyl groups at 3 positions (Scheme 1) and their application as ligands for $\mathrm{Ti}(\mathrm{IV})$ complexes to lead novel BINOL-titanium catalysts. These congested BINOLs with bulky tertiary alkyl substituents exhibit an enhanced chiral activity for the alkylation of aldehydes with enantioselectivities comparable to or higher than those achieved with original BINOL.

\section{RESULTS AND DISCUSSION}

The new $(R)$-BINOLs bearing bulky tertiary alkyl groups were prepared with excellent overall yields according to the route outlined in Scheme 1. The synthesis of 3-substituted BINOLs (R)-1,2,3 was performed in one step, in the presence of two, three, or four equivalents of 1-adamantanol and sulfuric acid as the catalyst; these reactions can be made at the multigram scale because of its high yield (>95\%) and easy purification. Under the mild conditions employed, the stereoconfiguration of BINOL is maintained. Thus, it was decided to introduce two adamantyl groups on 6,6'-di-t-butyl-BINOL (4) using similar conditions as described for BINOL 1 . In this case, the insertion of the bulky groups was carried out in the 3 and $3^{\prime}$ positions yielding the BINOL $\mathbf{5}$.

Received: December 19, 2017

Accepted: January 9, 2018

Published: January 30, 2018 
Scheme 1. Synthesis of Optically Pure (R)-BINOLs 1-5

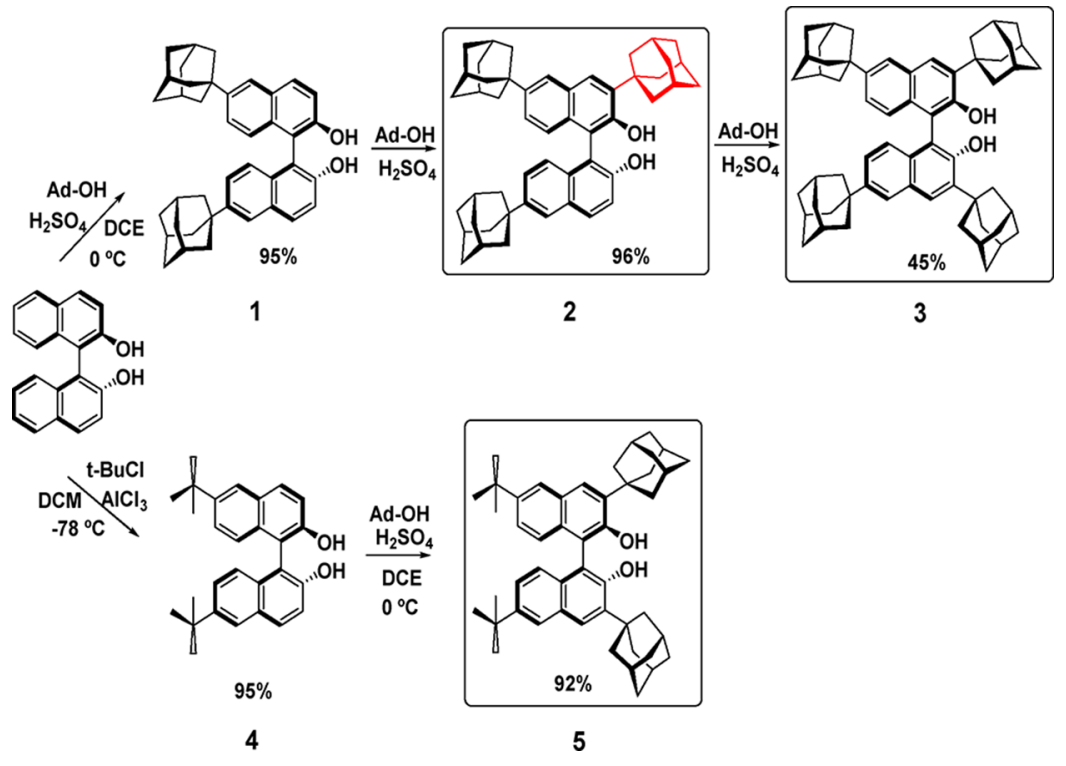

The known (R)-6,6'-di-t-butyl-[1,1'-binaphthalene]-2,2' -diol $(4)^{5}$ and (R)-6,6'-di(adamantan-1-yl)-[1,1'-binaphthalene]$2,2^{\prime}$-diol $(1)^{6}$ were obtained from tert-butyl chloride and 1adamantanol, respectively, as described before and applied as a reference for comparative purposes.

To demonstrate the synthetic utility of the highly active catalysts derived from the ligands BINOLs 1-5 (Scheme 1) and the parent $(R)$-BINOL, we examined the enantioselective addition of diethylzinc to various aromatic and aliphatic aldehydes catalyzed by $\mathrm{Ti}(\mathrm{IV})$ complex (Tables $1-3$ ). This

Table 1. BINOLs 1-5 for the Catalytic Asymmetric Ethylation of Benzaldehyde ${ }^{a}$

\begin{tabular}{|c|c|c|c|}
\hline entry & catalyst & yield $(\%)^{b}$ & ee $(\%)^{c, d}$ \\
\hline 1 & $1-[\mathrm{Ti}]$ & 91 & 87.0 \\
\hline 2 & $2-[\mathrm{Ti}]$ & $>98$ & 98.0 \\
\hline 3 & $3-[\mathrm{Ti}]$ & 44 & 84.1 \\
\hline 4 & $4-[\mathrm{Ti}]$ & 94 & 86.0 \\
\hline 5 & $5-[\mathrm{Ti}]$ & 95 & 88.2 \\
\hline 6 & BINOL-[Ti] & 91 & 90.6 \\
\hline
\end{tabular}

${ }^{a}$ Reaction conditions: BINOL/[Ti]/aldehyde/[Zn] (0.1/1.4/1.0/3.0). ${ }^{b}$ Reaction time: $1 \mathrm{~h}$, yield determined by gas chromatography (GC) with dodecane as the internal reference. ${ }^{c}$ Measured by GC using a CPChirasil-Dex chiral column. ${ }^{d}$ Absolute configuration was assigned by comparison with the product known from the literature. ${ }^{11}$

enantioselective reaction is a known method for the formation of carbon-carbon bonds, ${ }^{7}$ which has become recognized as a standard assay in guiding new ligand development. ${ }^{8,9}$ Reactions were carried out by using 2.4 equiv of diethylzinc ( $1 \mathrm{M}$ solution in hexane) at room temperature for $1-5 \mathrm{~h}$ in the presence of 0.1 equiv of all developed ligands and 3.0 equiv of $\mathrm{Ti}\left(\mathrm{O}^{i} \mathrm{Pr}\right)_{4}$ in toluene as the solvent; we started by using benzaldehyde as a test substrate to examine the efficiency of the chiral ligands (Table 1).
Table 2. Effect of Temperature on the Enantiomeric Excess for the 5-[Ti]-Catalyzed Ethylation of Benzaldehyde ${ }^{a}$

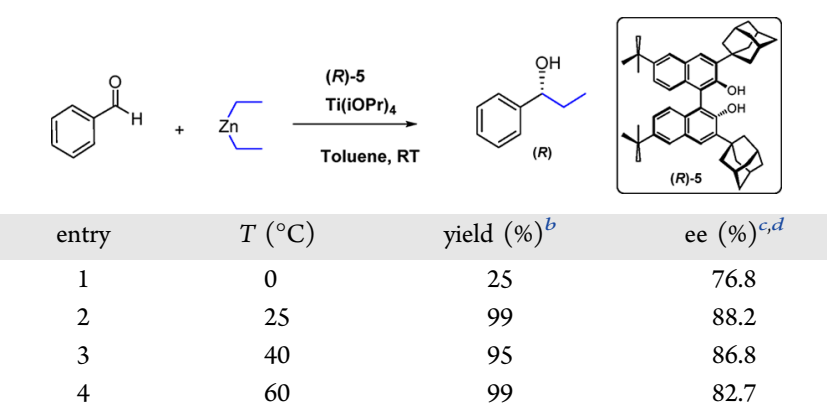

${ }^{a}$ Reaction conditions: BINOL/[Ti]/aldehyde/[Zn] (0.1/1.4/1.0/3.0). ${ }^{b}$ Determined by GC after $2 \mathrm{~h}$ reaction using dodecane as the internal reference. ${ }^{c}$ Measured by GC using a CP-Chirasil-Dex chiral column. ${ }^{d}$ Absolute configuration was assigned by comparison with the product known from the literature. ${ }^{11}$

Table 3. Non- $\mathrm{C}_{2}$ Symmetric 2-[Ti] Catalysts for the Asymmetric Ethylation of Aldehydes ${ }^{a}$

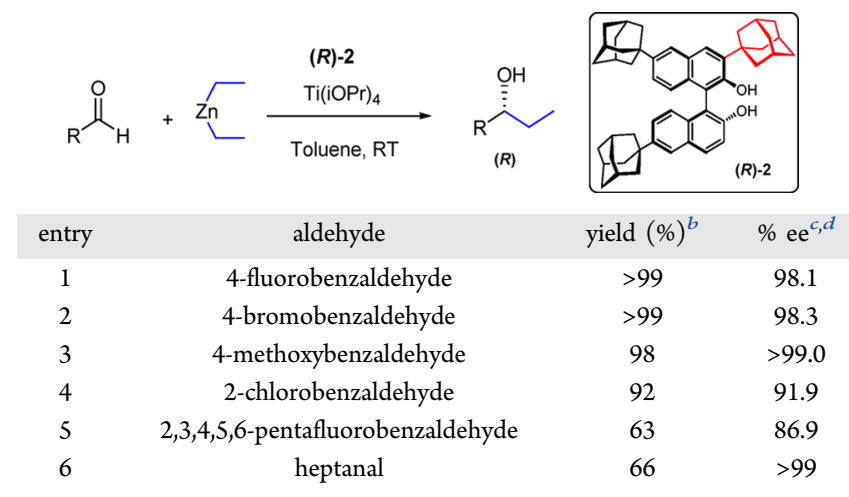

${ }^{a}$ Reaction conditions: BINOL/[Ti]/aldehyde/Et ${ }_{2} \mathrm{Zn}$ (0.1/1.4/1.0/ 3.0). ${ }^{b}$ Reaction time: 30 min. Yield determined by GC in the presence of dodecane as the internal reference. ${ }^{c}$ Measured by GC using a CP-Chirasil-Dex chiral column. ${ }^{d}$ Absolute configuration was assigned by comparison with the product known from the literature. $^{13,14}$ 
It has been reported for several studied catalytic systems that bulky groups at 6 and $6^{\prime}$ positions exert an increase in the dihedral angle between both naphthol rings, through repulsion forces, and a consequence gave an enhanced performance of 6,6'-substituted BINOLs over parent BINOL as a chiral ligand were observed. ${ }^{10}$ However, we have observed that for the ethylation of benzaldehyde, the presence of bulky substituents $6,6^{\prime}$-di-t-butyl or 6,6'-di-adamantyl groups into the BINOL rings leads not only to higher reactivity but also to similar enantioselectivities (Table 1) than pristine BINOL. In view of these results, we sought to test chiral BINOLs 2 and 5 having these bulky groups at $3,3^{\prime}$ positions; since, it is well-known that this substitution dramatically alters the chiral environment of the substrates' binding site, indeed from results, presented in Table 1, one can observe that the non- $\mathrm{C}_{2}$ symmetric trisubstituted BINOL 2 has the best catalytic performance with excellent yield and enantioselection (entry 2); tetrasubstituted BINOL 5 also show high yield and good enantioselectivity better than that of BINOLs 4, 1, which give similar results to that obtained with pristine BINOL. These results demonstrated that the incorporation of a new adamantyl group in 3 positions on 6,6'-disubstituted BINOLs is essential for high yields and enantioselections. When the reaction was carried out in the absence of the ligand, racemic alcohol was obtained.

To optimize the reaction conditions of the catalytic system, we achieved a variation of the reaction temperature for the ethylation reaction of benzaldehyde with $(R)-5-[T i]$ (Table 2). The relationship between reaction temperature and enantiomeric excess was investigated between 0 and $60{ }^{\circ} \mathrm{C}$. For our system, either raising or lowering the reaction temperature has a deleterious effect on the reaction selectivity; the enantiomeric excess obtained varies from 70 to $88 \%$. Such a behavior can be rationalized according to the isoinversion principle. The occurrence of inversion points is very common through a variety of selective processes. ${ }^{12}$ When the ethylation reaction was carried out at room temperature, an improved selectivity of $88 \%$ ee was obtained; this fact indicates that the isoinversion temperature is situated around $25{ }^{\circ} \mathrm{C}$. Although the obtained enantiomeric excess was $88 \%$ at the isoinversion temperature, 5 -[Ti] remains less effective than its single ( $R$ )-BINOL counterpart; therefore, we chose $\mathbf{2}$-[Ti] as the catalytic system to explore the scope of the reaction.

Under the optimized reaction temperature, $25^{\circ} \mathrm{C}$, the scope of the present reaction for the enantioselective ethylation of aldehydes was examined using $\mathbf{2}$ as the ligand (results in Table 3). 2-[Ti] catalyst showed excellent enantioinduction for a range of aldehydes. Alcohols generated from ethylation of $\mathrm{p}$ substituted benzaldehydes result in high yield and enantioselectivity (entries 1-3). The reaction of electron-rich aldehyde such as $p$-methoxybenzaldehyde resulted in high yield and enantioselectivity (entry 3 ). On the other hand, o-bromobenzaldehyde exhibited lower enantioselectivity (entry 4). The alcohol from 2,3,4,5,6-pentafluorobenzaldehyde was obtained in lower yield and requires longer reaction times to complete the reaction (entry 5). The reaction of aliphatic aldehyde heptanal proceeded with a relatively good yield to provide the corresponding alcohol with high enantioselectivity (entry 6); in this case, ethylation required prolonged reaction times to achieve the whole conversion.

\section{CONCLUSIONS}

In summary, we have prepared, in one step, new highly efficient enantiopure $(R)$-BINOLs bearing tertiary bulky groups (adamantyl and $t$-butyl) from commercially available starting materials. The activity of the chiral titanium catalyst derived from unsymmetrical 3,6,6'-trisubstituted BINOL-2 is significantly enhanced, and the enantioselectivity reached $99 \%$ in almost $30 \mathrm{~min}$ across a range of substrates. Further studies to incorporate the substituted-BINOLs into a porous polymer network are in progress now.

\section{ASSOCIATED CONTENT}

\section{Supporting Information}

The Supporting Information is available free of charge on the ACS Publications website at DOI: 10.1021/acsomega.7b02013.

Experimental procedures, characterizations, and analytical data of BINOL catalysts and nuclear magnetic resonance and GC traces of reaction products (PDF)

\section{AUTHOR INFORMATION}

\section{Corresponding Authors}

*E-mail: marta.iglesias@icmm.csic.es (M.I.).

*E-mail: felix-iqo@iqog.csic.es (F.S.).

ORCID

Rodrigo Navarro: 0000-0001-6592-9871

Marta Iglesias: 0000-0001-7373-4927

Félix Sánchez: 0000-0003-4069-1291

\section{Author Contributions}

The manuscript was written through contributions from all authors. All authors have given approval to the final version of the manuscript.

\section{Notes}

The authors declare no competing financial interest.

\section{ACKNOWLEDGMENTS}

Authors acknowledge MINECO of Spain (project MAT201452085-C2-2-P) for the financial support, and R.N. gratefully thanks a contract of Postdoctoral Formation program.

\section{REFERENCES}

(1) (a) Soai, K.; Niwa, S. Enantioselective addition of organozinc reagents to aldehydes. Chem. Rev. 1992, 92, 833-856. (b) Pu, L.; Yu, H.-B. Catalytic asymmetric organozinc additions to carbonyl compounds. Chem. Rev. 2001, 101, 757-824. (c) Lin, G. Q.; Li, Y. M.; Chan, A. S. C. Principles and Applications of Asymmetric Synthesis; John Wiley \& Sons: New York, 2001. (d) Harada, T. Development of Highly Active Chiral Titanium Catalysts for the Enantioselective Addition of Various Organometallic Reagents to Aldehydes. Chem. Rec. 2016, 16, 1256-1273.

(2) (a) Fürstner, A.; Albert, M.; Mlynarski, J.; Matheu, M.; DeClercq, E. Structure Assignment, Total Synthesis, and Antiviral Evaluation of Cycloviracin $\mathrm{B}_{1}$. J. Am. Chem. Soc. 2003, 125, 13132-13142. (b) Kondo, K.; Kan, K.; Tanada, Y.; Bando, M.; Shinohara, T.; Kurimura, M.; Ogawa, H.; Nakamura, S.; Hirano, T.; Yamamura, Y.; Kido, M.; Mori, T.; Tominaga, M. Characterization of orally active nonpeptide vasopressin $\mathrm{V}(2)$ receptor agonist. Synthesis and biological evaluation of both the $(5 R)$ - and $(5 S)$-enantioisomers of 2-[1-(2chloro-4-pyrrolidin-1-yl-benzoyl)-2,3,4,5-tetrahydro-1H-1-benzazepin5-yl]-N-isopropylacetamide. J. Med. Chem. 2002, 45, 3805-3808.

(3) (a) Harada, T.; Kanda, K. Enantioselective Alkylation of Aldehydes Catalyzed by a Highly Active Titanium Complex of 3Substituted Unsymmetric BINOL. Org. Lett. 2006, 8, 3817-3819. (b) Adate, P. A.; Matsunaga, T.; Shin, H.; Harada, T. Chiral Aluminum 
Catalyst System for the Enantioselective Addition of Vinylaluminum Reagents to Aldehydes: Metal Controlled Reversal of Enantioselectivity. Adv. Synth. Catal. 2016, 358, 3688-3693. (c) Hayashi, Y.; Yamamura, N.; Kusukawa, T.; Harada, T. Enhancement of the Catalytic Activity of Chiral $\mathrm{H}_{8}$-BINOL Titanium Complexes by Introduction of Sterically Demanding Groups at the 3-Position. Chem.-Eur. J. 2016, 22, 12095-12105.

(4) Pellisier, H. Enantioselective Titanium-Catalysed Transformations; Hutchings, H. G., Ed.; Imperial College Press: London, 2016; pp 187196.

(5) Chen, F.-X.; Yang, J.; Wu, S. Chiral Sodium Phosphate Catalyzed Enantioselective 1,4-Addition of TMSCN to Aromatic Enones. Synlett 2010, 2725-2728.

(6) Balaraman, E.; Swamy, K. C. K. A convenient chromatographyfree access to enantiopure 6,6'-di-tert-butyl-1,1'-binaphthalene-2,2' diol and its 3,3'-dibromo, di-tert-butyl and phosphorus derivatives: utility in asymmetric synthesis. Tetrahedron: Asymmetry 2007, 18, 2037-2048.

(7) Soai, K.; Shibata, T. Comprehensive Asymmetric Catalysis; Jacobsen, E. N., Pfaltz, A., Yamamoto, H., Eds.; Springer: Berlin, 1999; Vol. 2, pp 911-922.

(8) For representative work on the screening of new ligands monitored by organozinc addition to aldehydes, see: (a) Richmond, M. L.; Seto, C. T. Modular Ligands Derived from Amino Acids for the Enantioselective Addition of Organozinc Reagents to Aldehydes. J. Org. Chem. 2003, 68, 7505-7508. (b) Yus, M.; Ramón, D. J.; Prieto, $\mathrm{O}$. Synthesis of new $\mathrm{C}_{2}$-symmetrical bis(hydroxycamphorsulfonamide) ligands and their application in the enantioselective addition of dialkylzinc reagents to aldehydes and ketones. Tetrahedron: Asymmetry 2003, 14, 1103-1114. (c) Bauer, T.; Tarasiuk, J. $\alpha$-Hydroxy carboxylic acids: new ligands for diethylzinc additions to aldehydes. Tetrahedron Lett. 2002, 43, 687-689. (d) Page, P. C. B.; Allin, S. M.; Maddocks, S. J.; Elsegood, M. R. J. New ligands for asymmetric diethylzinc additions to aromatic aldehydes, demonstrating substrate-dependent nonlinear effects. J. Chem. Soc., Perkin Trans. 1 2002, 2827. (e) Priego, J.; Mancheño, O. G.; Cabrera, S.; Carretero, J. C. Aminosubstituted tertbutylsulfinylferrocenes as a new family of chiral ligands: asymmetric addition of diethylzinc to aldehydes. Chem. Commun. 2001, 2026. (f) Kostova, K.; Genov, M.; Philipova, I.; Dimitrov, V. New bissteroidal axially chiral diols as ligands for the asymmetric addition of diethylzinc to aldehydes. Tetrahedron: Asymmetry 2000, 11, 32533256. (g) Chen, Y.-X.; Yang, L.-W.; Li, Y.-M.; Zhou, Z.-Y.; Lam, K.-H.; Chan, A. S. C.; Kwong, H.-L. Synthesis of a new chiral ligand, 6,6'dihydroxy-5,5'-biquinoline (BIQOL) and its applications in the asymmetric addition of diethylzinc to aldehydes. Chirality 2000, 12, 510-513. (h) Bae, S. J.; Kim, B. M.; Kim, S.-W.; Hyeon, T. New chiral heterogeneous catalysts based on mesoporous silica: asymmetric diethylzinc addition to benzaldehyde. Chem. Commun. 2000, 31-32.

(9) Balsells, J.; Davis, T. J.; Carroll, P.; Walsh, P. J. Insight into the Mechanism of the Asymmetric Addition of Alkyl Groups to Aldehydes Catalyzed by Titanium-BINOLate Species. J. Am. Chem. Soc. 2002, 124, 10336-10348.

(10) Kim, J. G.; Camp, E. H.; Walsh, P. J. Catalytic Asymmetric Methallylation of Ketones with an $\left(\mathrm{H}_{8}\right.$-BINOLate $)$ Ti-Based Catalyst. Org. Lett. 2006, 8, 4413-4416.

(11) Paul, C. E.; Lavandera, I.; Gotor-Fernández, V.; Kroutil, W.; Gotor, V. Escherichia coli/ADH-A: An All-Inclusive Catalyst for the Selective Biooxidation and Deracemisation of Secondary Alcohols. ChemCatChem 2013, 5, 3875-3881.

(12) (a) Buschmann, H.; Scharf, H.-D.; Hoffmann, N.; Esser, P. The Isoinversion Principle-a General Model of Chemical Selectivity. Angew. Chem., Int. Ed. Engl. 1991, 30, 477-515. (b) Heller, D.; Buschmann, H.; Scharf, H.-D. Nonlinear Temperature Behavior of Product Ratios in Selection Processes. Angew. Chem., Int. Ed. Engl. 1996, 35, 1852-1854. (c) Ilg, M. K.; Wolf, L. M.; Mantilli, L.; Farès, C.; Thiel, W.; Fürstner, A. A Striking Case of Enantioinversion in Gold Catalysis and Its Probable Origins. Chem.-Eur. J. 2015, 21, 1227912284. (d) Matusmoto, A.; Fujiwara, S.; Hiyoshi, Y.; Zawatzky, K.; Makarov, A. A.; Welch, C. J.; Soai, K. Unusual reversal of enantioselectivity in the asymmetric autocatalysis of pyrimidyl alkanol triggered by chiral aromatic alkanols and amines. Org. Biomol. Chem. 2017, 15, 555-558.

(13) Huang, H.; Zong, H.; Bian, G.; Song, L. Chemo- and Enantioselective Addition and $\beta$-Hydrogen Transfer Reduction of Carbonyl Compounds with Diethylzinc Reagent in One Pot Catalyzed by a Single Chiral Organometallic Catalyst. J. Org. Chem. 2015, 80, 12614-12619.

(14) Faigl, F.; Deák, S. Z.; Erdélyi, Z. S.; Holczbauer, T.; Czugler, M.; Nyerges, M.; Mátravölgyi, B. New Atropisomeric Amino Alcohol Ligands for Enantioselective Addition of Diethylzinc to Aldehydes. Chirality 2015, 27, 216-222. 